\title{
Psychological wellbeing and sleep quality parameters response to life style intervention in non-alcoholic steatohepatitis obese patients
}

\begin{abstract}
Background: Non-alcoholic steatohepatitis (NASH) is a common progressive chronic hepatic disorder that has no approved treatment. Obesity is usually associated with NASH Life style intervention is the standard management of NASH. Objective: The purpose of current study was to detect psychological wellbeing and sleep quality parameters changes following Life style intervention in non-alcoholic steatohepatitis obese patients. Material and Methods: Fifty NASH patients of Internal Medicine Department at King Abdul Aziz University Hospital of both gender (27males \& 23females). The mean of their age was $46.11 \pm 4.95$ year, the mean of their BMI was $33.76 \pm 3.12 \mathrm{Kg} / \mathrm{m}^{2}$. Exclusion criteria included smokers, cardiovascular disorders, alcohol intake and renal failure. Participants assigned into two groups; group (A) conducted a 3months of life intervention program of exercise and diet control, while group (B) considered the control group. Results: The mean values of BMI, depression (BDI), total mood disturbance (POMS), awake time after sleep onset and REM sleep latency were significantly decreased, where the mean value of self esteem (RSES), total sleep duration, sleep efficiency and sleep onset latency were significantly increased as result of reduced body weight in group (A), while results of group (B) showed no significant changes. Conclusion: Weight reduction modulates psychological wellbeing and sleep quality parameters following Life style intervention in non-alcoholic steatohepatitis obese patients.
\end{abstract}

Volume 7 Issue 4 - 2019

Ziyad A Neamatallah, Afnan M AlKhateeb, Umar M Alabasi, Saad S AlFawaz

Department of Physical Therapy, Faculty of Medical Rehabilitation

Sciences, King Abdulaziz University, Saudi Arabia

Correspondence: Ziyad A Neamatallah, Faculty of Medical Rehabilitation Sciences, Department of Physical Therapy, King Abdulaziz University, P.O. Box 80324, Jeddah, 2 1 589, Saudi Arabia, Email dr.zneamatallah@gmail.com

Received: June 05, 2019 | Published: July 23, 2019

Keywords: anxiety, depression, psychological wellbeing, sleep parameters, nonalcoholic steatohepatitis, weight loss.

\section{Introduction}

Non-alcoholic steatohepatitis (NASH) is a prevalent medical problem about $4 \%$ of adults worldwide; ${ }^{1,2}$ which is parallel with the high risk of obesity. ${ }^{3}$ The mortality rate among patients with NASH is great due to the associated cardiovascular and hepatic complications. ${ }^{4}$ In addition, risk of psychiatric disorders are higher among obese subjects. ${ }^{5,6}$

Increased body mass index (BMI) is directly correlated with risk of sleep disorders, reduced sleep duration and poor quality of sleep. ${ }^{\text {? }}$ However, there is a close link between obesity and nonalcoholic fatty liver disease (NAFLD) along with risk of sleep disturbance. ${ }^{8-11}$ Other studies reported an association between risk of NAFLD and short sleep duration \& poor quality of sleep..$^{12,13}$ In the other hand, sleep disruption was reported as a contributing factor in the pathogenesis and development of the NAFLD. ${ }^{14,15}$

Chronic hepatic disorders are usually associated with higher depression rate. ${ }^{16}$ While, Russ and colleagues found an association between NAFLD/NASH and psychological distress as emotional symptoms are common among patients with chronic hepatic disorders. ${ }^{17}$ Moreover, anxiety and depressive symptoms found to be associated with NAFLD and other liver diseases. ${ }^{18-23}$

Exercise and diet control cons, ${ }^{24-28}$ Weight loss is usually associated with many health benefits as modulation of live enzymes, ${ }^{29-32}$ reduction of liver fat, ${ }^{33-36}$ improved activity score and severity of NAFLD,${ }^{37}$ in addition to resolution of depressive symptoms. ${ }^{38}$
The current study aimed to detect psychological wellbeing and sleep quality parameters changes following life style intervention in non-alcoholic steatohepatitis obese patients.

\section{Material and methods}

\section{Subjects}

Fifty NASH patients of Internal Medicine Department at King Abdul Aziz University Hospital of both gender (27males \& 23 females). The mean of their age was $46.11 \pm 4.95$ year, the mean of their BMI was $33.76 \pm 3.12 \mathrm{Kg} / \mathrm{m}^{2}$. Exclusion criteria included smokers, cardiovascular disorders, alcohol intake and renal failure. Participants assigned into two groups; group (A) conducted a 3months of life intervention program of exercise and diet control, while group (B) considered the control group.

\section{Measurements}

Psychological well-being: Self esteem that include ten items was measured using the Rosenberg Self Esteem Scale (RSES), while mood disturbances was measured by the Profile of Mood States (POMS) that include 65 items and depression was measured by Depression Inventory (BDI) that consists of 21 items. ${ }^{39}$

Sleep parameters: Polysomnographic (PSG) recording was conducted for all participants over 48 hours using the digital system (Philips-Respironics, USA). The sleep parameters measured included total sleep time, sleep latency, sleep efficiency, awake after sleep 
onset, REM sleep latency. ${ }^{40}$ The above parameters were measured at the beginning and after 90days at the end of the study.

\section{Procedures}

The training group: Twenty five NASH patients enrolled in the training group by doing aerobic exercise program in addition to diet control. Treadmill (Track master 400E, gas fitness system, England) was used to do aerobic training program with intensity about $70 \%$ to $80 \%$ of the maximum heart rate (HRmax), three training sessions every week for 12 weeks, each session consisted of 5 minutes warming up, 30minutes aerobic training and 5minutes cooling down. The diet control was conducted under close supervision of dietitian who designed each the total energy intake 1200Kilocalories/day with balanced diet (protein $=15 \%$, fat $=30$ to $35 \%$ and carbohydrate $=50$ to $55 \%$ ) for three months.

The control group: Twenty five NASH patients shared in this study as a control group by keeping their usual life style and received no treatment intervention.

\section{Statistical analysis}

Comparison of the significance for the mean values of the measured parameters at the start and at the end of the study in two groups were compared using student paired "t" test. While, student unpaired " $t$ " test was used in comparison between the two groups $(\mathrm{P}<0.05)$.

\section{Results}

The baseline and biochemical parameters of the study are presented in Table 1 which proved that there was no significant differences between the intervention group(A) and the control group (B) that means we have two homogenous groups. Regarding the values of BMI, Depression (BDI), Total mood disturbance (POMS), Awake time after sleep onset and REM sleep latency they obtained significant reduction in group (A), where the values of Self esteem (RSES), Total sleep duration' Sleep efficiency and Sleep onset latency they obtained significant increase (Table 2), while results of group (B) showed no significant changes (Table 3). In addition; no significant difference recoded between both groups at the end of the study (Table 4).

Table I Baseline and biochemical parameters of participants

\begin{tabular}{|c|c|c|c|}
\hline & \multicolumn{2}{|l|}{ Mean $\pm S D$} & \multirow{2}{*}{ Significance } \\
\hline & Group(A) & Group(B) & \\
\hline Age(year) & $44.95 \pm 5.28$ & $42.51 \pm 4.93$ & $P>0.05$ \\
\hline Gender(male/female) & $|4 /| \mid$ & $13 / 12$ & $P>0.05$ \\
\hline $\operatorname{BMI}\left(\mathrm{kg} / \mathrm{m}^{2}\right)$ & $34.73 \pm 4.64$ & $33.4 I \pm 4.59$ & $P>0.05$ \\
\hline $\mathrm{SBP}(\mathrm{mm} \mathrm{Hg})$ & $146.14 \pm 11.13$ & $144.75 \pm 10.78$ & $P>0.05$ \\
\hline $\mathrm{DBP}(\mathrm{mm} \mathrm{Hg})$ & $89.26 \pm 5.37$ & $87.94 \pm 5.42$ & $P>0.05$ \\
\hline Total cholesterol(mg/dl) & $197.38 \pm 16.69$ & $195.22 \pm \mid 4.84$ & $P>0.05$ \\
\hline HDL-C(mg/dl) & $35.65 \pm 4.21$ & $36.51 \pm 3.93$ & $P>0.05$ \\
\hline LDL-C(mg/dl) & $121.18 \pm 10.54$ & $118.96 \pm 9.25$ & $P>0.05$ \\
\hline Triglycerides(mg/dl) & $154.37 \pm 9.16$ & $153.15 \pm 8.73$ & $P>0.05$ \\
\hline AST(IU) & $65.44 \pm 5.72$ & $63.83 \pm 4.94$ & $P>0.05$ \\
\hline $\operatorname{ALT}(I U)$ & $53.52 \pm 4.45$ & $52.21 \pm 4.32$ & $P>0.05$ \\
\hline
\end{tabular}

BMI, body mass index; SBP, systolic blood pressure; DBP, diastolic blood pressure; HOMA-IR, homeostasis model assessment-insulin resistance index; HDL-c, high density lipoprotein cholesterol; LDL-c, Low density lipoprotein cholesterol; AST, aspartate aminotransferase; ALT, alanine aminotransferase.

Table 2 Mean value and significance of measured variables of group(A) before and at the end of the study

\begin{tabular}{lllll}
\hline & Mean \pm SD & & \\
\cline { 2 - 3 } & Before & After & T-value & Significance \\
\hline BMl $\left(\mathrm{kg} / \mathrm{m}^{2}\right)$ & $34.73 \pm 4.64$ & $27.56 \pm 3.21^{*}$ & 7.32 & $\mathrm{P}<0.05$ \\
Self-esteem(RSES) & $23.41 \pm 4.32$ & $26.38 \pm 4.24^{*}$ & 7.27 & $\mathrm{P}<0.05$ \\
Depression(BDI) & $8.26 \pm 1.98$ & $6.11 \pm 1.76^{*}$ & 6.76 & $\mathrm{P}<0.05$ \\
\hline
\end{tabular}


Table Continued...

\begin{tabular}{|c|c|c|c|c|}
\hline & \multicolumn{2}{|l|}{ Mean士SD } & \multirow{2}{*}{ T-value } & \multirow{2}{*}{ Significance } \\
\hline & Before & After & & \\
\hline Total mood disturbance(POMS) & $25.17 \pm 2.76$ & $21.25 \pm 2.85^{*}$ & 7.19 & $P<0.05$ \\
\hline Total sleep duration(min) & $316.16 \pm 25.31$ & $335.34 \pm 27.12^{*}$ & 9.21 & $P<0.05$ \\
\hline Sleep efficiency(\%) & $73.25 \pm 11.37$ & $80.19 \pm 10.13^{*}$ & 8.24 & $P<0.05$ \\
\hline Sleep onset latency (min) & $12.34 \pm 2.28$ & $|6.15 \pm 2.6|^{*}$ & 6.82 & $P<0.05$ \\
\hline Awake time after sleep onset(min) & $79.23 \pm 9.34$ & $66.52 \pm 8.37^{*}$ & 8.32 & $P<0.05$ \\
\hline REM sleep latency $(\mathrm{min})$ & $80.62 \pm 10.48$ & $68.38 \pm 9.22 *$ & 6.95 & $P<0.05$ \\
\hline
\end{tabular}

BMI, body mass index; RSES, rosenberg self-esteem scale; BDI, beck depression inventory; POMS, profile of mood states; REM, rapid eye movements; (*) indicates a significant difference between the two groups; $P<0.05$.

Table 3 Mean value and significance of Mean value and significance of measured variables of group(B) before and at the end of the study

\begin{tabular}{|c|c|c|c|c|}
\hline & \multicolumn{2}{|l|}{ Mean士SD } & \multirow{2}{*}{ T-value } & \multirow{2}{*}{ Significance } \\
\hline & Before & After & & \\
\hline $\mathrm{BMI}\left(\mathrm{kg} / \mathrm{m}^{2}\right)$ & $33.41 \pm 4.59$ & $34.22 \pm 4.64$ & 0.87 & $P>0.05$ \\
\hline Self-esteem(RSES) & $21.82 \pm 3.97$ & $20.91 \pm 4.11$ & 0.92 & $P>0.05$ \\
\hline Depression(BDI) & $7.99 \pm 1.76$ & $8.33 \pm 1.79$ & 0.79 & $P>0.05$ \\
\hline Total mood disturbance(POMS) & $23.79 \pm 3.92$ & $24.11 \pm 3.97$ & 0.88 & $P>0.05$ \\
\hline Total sleep duration(min) & $321.4 I \pm 26.18$ & $317.75 \pm 25.41$ & 1.76 & $P>0.05$ \\
\hline Sleep efficiency(\%) & $74.58 \pm 10.64$ & $73.23 \pm 10.71$ & 1.54 & $P>0.05$ \\
\hline Sleep onset latency(min) & $|3.62 \pm 2.8|$ & $13.79 \pm 2.82$ & 0.95 & $P>0.05$ \\
\hline Awake time after sleep onset(min) & $78.76 \pm 8.16$ & $81.12 \pm 9.34$ & 0.83 & $P>0.05$ \\
\hline REM sleep latency(min) & $80.85 \pm 10.98$ & $79.41 \pm 11.19$ & 0.85 & $P>0.05$ \\
\hline
\end{tabular}

BMI, body mass index; RSES, rosenberg self-esteem scale; BDI, beck depression inventory; POMS, profile of mood states ; REM, rapid eye movements; (*) indicates a significant difference between the two groups; $\mathrm{P}<0.05$.

Table 4 Mean value and significance of Mean value and significance of measured variables of group $(A)$ and group(B) after treatment

\begin{tabular}{lllll}
\hline & Mean \pm SD & & T-value & Significance \\
\cline { 2 - 4 } & Group(A) & Group( B) & & $P<0.05$ \\
BMI $\left(\mathrm{kg} / \mathrm{m}^{2}\right)$ & $27.56 \pm 3.21^{*}$ & $34.22 \pm 4.64$ & 7.21 & $\mathrm{P}<0.05$ \\
Self-esteem(RSES) & $26.38 \pm 4.24^{*}$ & $20.91 \pm 4.11$ & 6.48 & $\mathrm{P}<0.05$ \\
Depression(BDI) & $6.11 \pm 1.76^{*}$ & $8.33 \pm 1.79$ & 5.12 & $\mathrm{P}<0.05$ \\
Total mood disturbance(POMS) & $21.25 \pm 2.85^{*}$ & $24.11 \pm 3.97$ & 4.97 & $\mathrm{P}<0.05$ \\
Total sleep duration(min) & $335.34 \pm 27.12^{*}$ & $317.75 \pm 25.41$ & 8.92 & $\mathrm{P}<0.05$ \\
Sleep efficiency(\%) & $80.19 \pm 10.13^{*}$ & $73.23 \pm 10.71$ & 6.57 & $\mathrm{P}<0.05$ \\
Sleep onset latency(min) & $16.15 \pm 2.61^{*}$ & $13.79 \pm 2.82$ & 4.93 & $\mathrm{P}<0.05$ \\
Awake time after sleep onset(min) & $66.52 \pm 8.37^{*}$ & $81.12 \pm 9.34$ & 6.38 & $\mathrm{P}<0.05$ \\
REM sleep latency(min) & $68.38 \pm 9.22^{*}$ & $79.41 \pm 11.19$ & 7.23 &
\end{tabular}

BMI, body mass index; RSES, rosenberg self-esteem scale; BDI, beck depression inventory; POMS, profile of mood states ; REM, rapid eye movements; (*) indicates a significant difference between the two groups; $P<0.05$. 


\section{Discussion}

For the best of our knowledge, the present study is the first one to measure the psychological wellbeing sleep quality parameters response to life style intervention in non-alcoholic steatohepatitis obese patients, as there is limited researches in this area even NASH and obesity are growing medical problems. The novelty of the present study is that weight reduction is considered as a cornerstone and only the standard treatment for the NASH and psychological distress and abnormal sleep parameters are common complains among obese patients with NASH ${ }^{41}$ Therefore, the purpose of current study was to detect psychological wellbeing and sleep quality parameters changes following life style intervention in non-alcoholic steatohepatitis obese patients.

Our results regrading influence of weight loss on psychological wellbeing, showed reduced BDI \& POMS and increased RSES, which agreed with many researches. ${ }^{42-46}$ Grave and colleagues and Imayama and coworkers stated that good results of psychological wellbeing and quality of life (QOL) obtained following 12months of weight reducing program. ${ }^{42,43}$ However, Wycherley and colleagues proved that 4months of weight reduction program resulted in resolution of psychological distress and good QOL in obese diabetic subjects. ${ }^{44}$ Similarly, Faulconbridge et al. ${ }^{45}$ reported that loss of weight positively changed the depressed mode in obese subjects. ${ }^{45}$

Regarding results sleep parameter, our results proved that sleep duration and quality positively improved with weight reducing program among NASH patients, these results approved with similar researches in other different disorders. ${ }^{46-51}$ Tan and colleagues stated that sleep onset latency shortened in obese men with insomnia after of six months of diet control. ${ }^{46}$ While, Tan et al ${ }^{46}$ reported that six months of weight reducing program of diet control and exercise improved sleep quality parameters in obese men with sleep disorders. ${ }^{47}$ However, Passos and coworkers proved that polysomnographic (PSG) recording of sleep quality improved after four months of aerobic exercise training in patients with chronic primary insomnia. ${ }^{48}$ Moreover, the possible mechanism of improving sleep quality following life style intervention may include: modulation of body temperature, weight loss, reduced secretion of inflammatory cytokines, increased secretion of endorphin and anti-inflammatory cytokines. ${ }^{49-51}$

\section{Conclusion}

Weight loss modulates psychological wellbeing and sleep quality parameters following life style intervention in non-alcoholic steatohepatitis obese patients.

\section{Acknowledgments}

None.

\section{Conflicts of interest}

The authors declare that there are no conflicts of interest

\section{Funding}

None.

\section{References}

1. Chalasani N, Younossi Z, Lavine JE, et al. The diagnosis and management of nonalcoholic fatty liver disease: practice guidance from the American Association for the Study of Liver Diseases. Hepatology. 2017;67(1):328-357.
2. Younossi ZM, Koenig AB, Abdelatif D, et al. Global epidemiology of nonalcoholic fatty liver disease-meta-analytic assessment of prevalence, incidence, and outcomes. Hepatology. 2016;64(1):73-84.

3. Canbay A, Sowa JP, Syn WK, et al. NASH cirrhosis - the new burden in liver transplantation: how should it be managed? Visc Med. 2016;32(4):234-38.

4. Rinella ME. Nonalcoholic fatty liver disease: a systematic review. JAM.A 2015;313(22):2263-2273.

5. Williamson DA, O’Neil PM. Behavioral and psychological correlates of obesity. In: Bray GA, et al, editors. Handbook of obesity. New York: Marcel Dekker Inc.; 1998. p. 129-42.

6. Werrij MQ, Mulkens S, Hospers HJ, et al. Overweight and obesity: the significance of a depressed mood. Patient Educ Couns. 2006;62(1):126131.

7. Meier-Ewert HK, Ridker PM, Rifai N, et al. Effect of sleep loss on Creactive protein, an inflammatory marker of cardiovascular risk. $\mathrm{J} \mathrm{Am}$ Coll Cardiol. 2004;43(4):678-683.

8. Zelber-Sagi S, Lotan R, Shlomai A, et al. Predictors for incidence and remission of NAFLD in the general population during a seven-year prospective follow-up. J Hepatol. 2012;56(5):1145-1151.

9. Kumashiro N, Erion DM, Zhang D, et al. Cellular mechanism of insulin resistance in nonalcoholic fatty liver disease. Proc Natl Acad Sci USA. 2011;108(39):16381-16385.

10. Kim CW, Yun KE, Jung HS, et al. Sleep duration and quality in relation to non-alcoholic fatty liver disease in middle-aged workers and their spouses. J Hepatol. 2013;59(2):351-357.

11. Mir HM, Stepanova M, Afendy H, et al. Association of Sleep Disorders with Nonalcoholic Fatty Liver Disease (NAFLD): A Population-based Study. J Clin Exp Hepatol. 2013;3(3):181-185.

12. Chou YT, Cheng HJ, Wu JS, et al. The association of sleep duration and sleep quality with non-alcoholic fatty liver disease in a Taiwanese population. Obes Res Clin Pract. 2018;12(6):500-505.

13. Kui $\mathrm{P}$, Lin L, Zhengyi W, et al. Short sleep duration and longer daytime napping are associated with non-alcoholic fatty liver disease in Chinese adults. J Diabetes. 2017;9(9):827e36.

14. Marin-Alejandre BA, Abete, Cantero I, et al. Association between Sleep Disturbances and Liver Status in Obese Subjects with Nonalcoholic Fatty Liver Disease: A Comparison with Healthy Controls. Nutrients. 2019;11(2):E322.

15. Kim JH, Jung DH, Kwon YJ, et al. The impact of the sleep duration on NAFLD score in Korean middle-aged adults: a community-based cohort study. Sleep Med. 2019;57:144-150.

16. Hermes JM, Mann-Deibert G, Hefner AM, et al. The correlation between depression and chronic hepatic conditions as measured by the PHQ-9 depression assessment accounting for social characteristics. Journal of Hepatology. 2015;62:S263-S864.

17. Russ TC, Kivimäki M, Morling JR, et al. Association Between Psychological Distress and Liver Disease Mortality: A Meta-analysis of Individual Study Participants. Gastroenterology. 2015;148(5):958-966. e4.

18. Stewart KE, Haller DL, Sargeant C, et al. Readiness for behaviour change in non-alcoholic fatty liver disease: implications for multidisciplinary care models. Liver Int. 2015;35(3):936-943.

19. Youssef NA, Abdelmalek MF, Binks M, et al. Associations of depression, anxiety, and antidepressants with histological severity of nonalcoholic fatty liver disease. Liver Int. 2013;33(7):1062-1070.

20. Elwing JE, Lustman PJ, Wang HL, et al. Depression, anxiety and nonalcoholic steatohepatitis. Psychosom Med. 2006;68(4):563-569. 
21. Weinstein AA, Kallman PriceJ, Stepanova M, et al. Depression in patients with nonalcoholic fatty liver disease and chronic viral hepatitis B and C. Psychosomatics. 2011;52(2):127-132.

22. Asnis GM, DeLa Garza RN2nd. Interferon-induced depression in chronic hepatitis $\mathrm{C}$ : a review of its prevalence, risk factors, biology, and treatment approaches. J Clin Gastroenterol. 2006;40(4):322-335.

23. Le Strat Y, Le Foll B, Dubertret C. Major depression and suicide attempts in patients with liver disease in the United States. Liver Int. 2015;35(7):1910-1916.

24. Trovato FM, Martines GF, Brischetto D, et al. Fatty liver disease and lifestyle in youngsters: diet, food intake frequency, exercise, sleep shortage and fashion. Liver Int. 2016;36(3):427-433.

25. Medrano M, Cadenas-Sanchez C, Alvarez-Bueno C, et al. Evidencebased exercise recommendations to reduce hepatic fat content in youth- a systematic review and meta-analysis. Prog Cardiovasc Dis. 2018;61(2):222-231

26. Utz-Melere M, Targa-Ferreira C, Lessa-Horta B, et al. Nonalcoholic fatty liver disease in children and adolescents: Lifestyle change - a Systematic review and meta-analysis. Ann Hepatol. 2018;17(3):345354 .

27. Nobili V, Alisi A, Raponi M. Pediatric non-alcoholic fatty liver disease: preventive and therapeutic value of lifestyle intervention. World $J$ Gastroenterol. 2009;15(48):6017-6022.

28. Chalasani N, Younossi Z, Lavine JE, et al. The diagnosis and managemen of non-alcoholic fatty liver disease: practice Guideline by the American Association for the Study of Liver Diseases, American College of Gastroenterology, and the American Gastroenterological Association. Hepatology. 2012;55(6):2005-2023.

29. Larson-Meyer DE, Newcomer BR, Heilbronn LK, et al. Effect of 6month calorie restriction and exercise on serum and liver lipids and markers of liver function. Obesity (Silver Spring). 2008;16(6):13551362 .

30. St George A, Bauman A, Johnston A, et al. Effect of a lifestyle intervention in patients with abnormal liver enzymes and metabolic risk factors. J Gastroenterol Hepatol. 2009;24(3):399-407.

31. de Luis DA, Aller R, Izaola O, et al. Effect of two different hypocaloric diets in transaminases and insulin resistance in nonalcoholic fatty liver disease and obese patients. Nutr Hosp. 2010;25(5):730-735.

32. Straznicky NE, Lambert EA, Grima MT, et al. The effects of dietary weight loss with or without exercise training on liver enzymes in obese metabolic syndrome subjects. Diabetes Obes Metab. 2012;14(2):139148 .

33. Petersen KF, Dufour S, Befroy D, et al. Reversal of nonalcoholic hepatic steatosis, hepatic insulin resistance, and hyperglycemia by moderate weight reduction in patients with type 2 diabetes. Diabetes. 2005;54(3):603-608

34. Haufe S, Engeli S, Kast P, et al. Randomized comparison of reduced fat and reduced carbohydrate hypocaloric diets on intrahepatic fat in overweight and obese human subjects. Hepatology. 2011;53(5):1504 1514.

35. Sullivan S, Kirk EP, Mittendorfer B, et al. Randomized trial of exercise effect on intrahepatic triglyceride content and lipid kinetics in nonalcoholic fatty liver disease. Hepatology. 2012;55(6):1738-1745.
36. Bozzetto L, Prinster A, Annuzzi G, et al. Liver fat is reduced by an isoenergetic MUFA diet in a controlled randomized study in type 2 diabetic patients. Diabetes Care. 2012;35(7):1429-1435.

37. Promrat K, Kleiner DE, Niemeier HM, et al. Randomized controlled trial testing the effects of weight loss on nonalcoholic steatohepatitis. Hepatology. 2010;51(1):121-129.

38. Faulconbridge LF, Wadden TA, Berkowitz RI, et al. Changes in symptoms of depression with weight loss: results of a randomized trial Obesity. 2009;17(5):1009-1016.

39. Palmeira A, Branco T, Martins S, etal. Change in body image and psychological well-being during behavioral obesity treatment: Associations with weight loss and maintenance. Body Image. 2010;7(3):187-193.

40. Rechtschaffen A, Kales AA. Manual of standardized terminology, techniques, and scoring system for sleep stages of human subjects. Los Angeles: Brain Information Service/Brain Research Institute/UCLA. 1968.

41. Deed G. Integrative care of type 2 diabetes mellitus. Advances in Integrative Medicine. 2014;1:55-58.

42. Grave R, Calugi S, Petroni M, et al. Weight management, psychologica distress and binge eating in obesity. A reappraisal of the problem. Appetite. 2010;54(2):269-273.

43. Imayama I, Alfano C, Kong A, et al. Dietary weight loss and exercise interventions effects on quality of life in overweight/obese postmenopausal women: a randomized controlled trial. International Journal of Behavioral Nutrition and Physical Activity. 2011;8:118-129.

44. Wycherley T, Clifton P, Noakes M, et al. Weight loss on a structured hypocaloric diet with or without exercise improves emotional distress and quality of life in overweight and obese patients with type 2 diabetes. Journal of Diabetes Investigation. 2014;5(1):94-98.

45. Faulconbridge L, Wadden T, Rubin R, et al. One-year changes in weight and symptoms of depression in depressed vs. non-depressed individuals in the Look AHEAD study. Obesity. 2009;2:576.

46. Tan X, Alén M, Wang K, et al. Effect of Six-Month Diet Intervention on Sleep among Overweight and Obese Men with Chronic Insomnia Symptoms: A Randomized Controlled Trial. Nutrients. 2016;8(11):E751.

47. Tan X, Saarinen A, Mikkola TM, et al. Effects of exercise and die interventions on obesity-related sleep disorders in men: study protocol for a randomized controlled trial. Trials. 2013;14:235.

48. Passos GS, Poyares D, Santana MG, et al. Exercise Improves Immune Function, Antidepressive Response, and Sleep Quality in Patients with Chronic Primary Insomnia. Biomed Res Int. 2014;2014:498961.

49. Driver HS, Taylor SR. Exercise and sleep. Sleep Medicine Reviews. 2000;4(4):387-402.

50. Yang PY, Ho KH, Chen $\mathrm{HC}$, et al. Exercise training improves sleep quality in middle-aged and older adults with sleep problems: a systematic review. J Physiother. 2012;58(3):157-163.

51. Kapsimalis F, Basta M, Varouchakis G, et al. Cytokines and pathological sleep. Sleep Med. 2008;9(6):603-14. 